\title{
Consistency in the behaviour types of the Atlantic cod: repeatability, timing of migration and geo-location
}

\author{
Vilhjálmur Thorsteinsson ${ }^{1}$, Ólafur K. Pálsson ${ }^{1}$, Gunnar G. Tómasson ${ }^{2}$, \\ Ingibjörg G. Jónsdóttir ${ }^{1}$, Christophe Pampoulie ${ }^{1, *}$ \\ ${ }^{1}$ Marine Research Institute, Skúlagata 4, 101 Reykjavík, Iceland \\ ${ }^{2}$ Reykjavik University, School of Science and Engineering, Menntavegur 1, 101 Reykjavík, Iceland
}

\begin{abstract}
We investigated the behaviour patterns of coastal (relatively stationary in shallow waters) and migratory frontal (offshore) types of Atlantic cod Gadus morhua in Icelandic waters using information from data storage tags (DSTs). Consistent and repeated patterns of migration were observed for both coastal and frontal cod, with characteristic DST profiles repeated from year to year. The migration timing in 2 successive years was close to being synchronous, suggesting that the onset of migration was consistent from year to year. A tidal location model suggested that the feeding migrations of cod in Icelandic waters were undertaken in groups or shoals during the whole year. The overall stability of the behaviour patterns of both types suggests that coastal and frontal individuals use different behavioural strategies which might either be related to food availability/competition or genetic control.
\end{abstract}

KEY WORDS: Gadus morhua $\cdot$ Iceland $\cdot$ Behaviour types $\cdot$ Seasonality $\cdot$ Feeding strategies

\section{INTRODUCTION}

Seasonal variations in the environment, and consequently variations in food supplies, continuously induce annual migrations of most species in birds, mammals or fishes over short or vast distances. Due to the development of promising tracking methods, migration studies have been flourishing in recent decades, with particular emphasis on multiple year patterns (Egevang et al. 2010, Klaassen et al. 2011, Matthews et al. 2011, Olifiers et al. 2011, Vardanis et al. 2011, Forsythe et al. 2012). In this context, data storage tags (DSTs) allow the investigation of thermo-bathymetric migration patterns of fish, and the variability of individual migrations, using relatively long-term storage DSTs (Neat et al. 2006). In Atlantic cod Gadus morhua L., individual behaviour related to feeding migrations has been shown to vary within a single spawning ground. Two behaviour types have been observed, i.e. a coastal, relatively stationary type in shallow waters, and a migratory frontal (offshore) type, breeding in shallow waters but migrating to deeper waters to commonly feed near thermal fronts (Nordeide 1998, Godo \& Michalsen 2000, Pálsson \& Thorsteinsson 2003, Neat et al. 2006). Both behaviour types have been studied in Norwegian (Nordeide 1998, Godo \& Michalsen 2000) and Icelandic waters (Pálsson \& Thorsteinsson 2003, Pampoulie et al. 2008a), and have been shown to segregate by depth both during spawning and feeding time (Nordeide 1998, Grabowski et al. 2011). Recent studies have also shown genotype differences at the pantophysin locus (Pan I, see Fevolden \& Pogson 1997, Sarvas \& Fevolden 2005, Skarstein et al. 2007, 
Pampoulie et al. 2008a). The pantophysin Pan $\mathrm{I}^{\mathrm{B}}$ allele was predominantly observed in northeast Arctic cod and in the Icelandic frontal type, while the Pan $\mathrm{I}^{\mathrm{A}}$ allele was predominantly observed in Norwegian coastal cod and in the Icelandic coastal type. However, despite intensive research on these 2 behaviour types, no studies have dealt with year-toyear repeatability of individual migrations, or the timing and routes of migrations. This information can be retrieved from DSTs (Hunter et al. 2004, Metcalfe 2006) and may shed new light on feeding migration processes (i.e. whether individuals move in groups/ shoals) and on the consistency of the migration habits of these behaviours.

We investigated the thermo-bathymetric migration patterns of the coastal and frontal behaviour types of Atlantic cod in Icelandic waters. Our main goal was to evaluate the repeatability of individual migration patterns and the timing of migrations within and between behaviour types. An attempt at geo-location of individuals of both behaviour types to assess whether individuals move in groups or shoals was also performed.

\section{MATERIALS AND METHODS}

The DSTs used were DSTmilli and DSTcenti-ex, produced by Star Oddi, and their characteristics were already described (Pampoulie et al. 2008a). The DSTcenti-ex recorded temperature and depth every

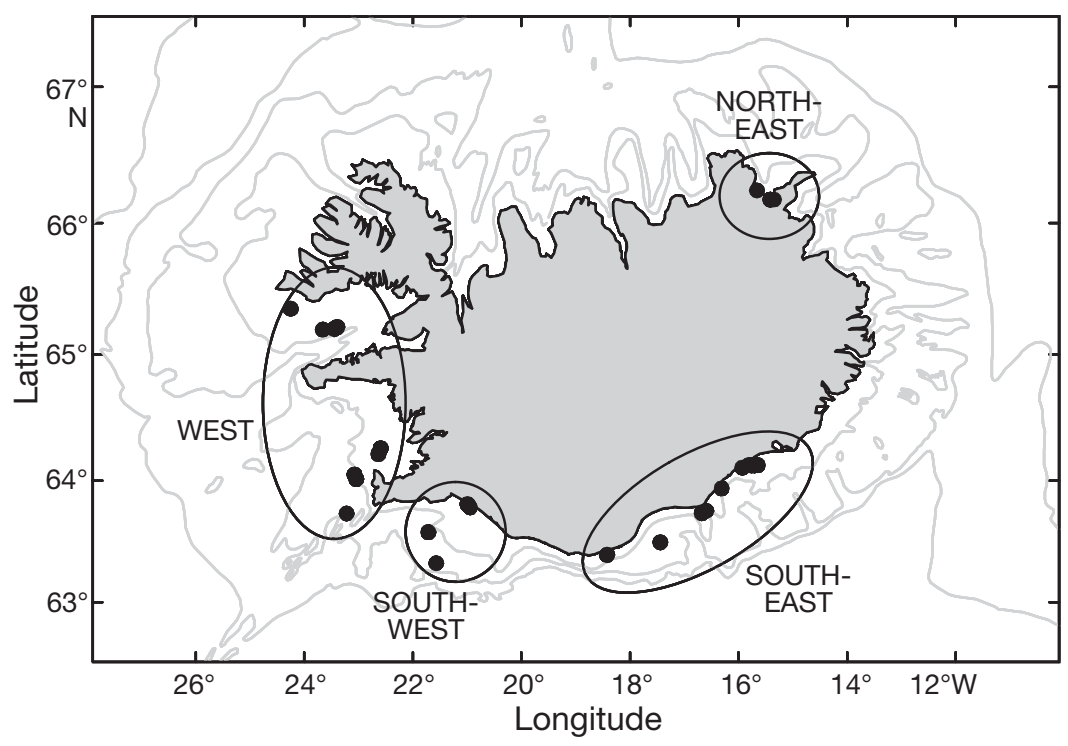

Fig. 1. Gadus morhua. Release areas of adult cod with data storage tags on spawning grounds in 2003 to 2005 that were recaptured after at least 18 mo. Depth contours at 100, 200, $500 \mathrm{~m}$
10 min during the first $2 \mathrm{yr}$. To extend the sampling time through the third year, the tags were set to a measuring frequency of $6 \mathrm{~h}$, except in April and October. The tagging procedure is fully described on the following web site: www.hafro.is/skrar/flokkar/ merkingar_thorskur.pdf.

During the years 2002 to 2005, 1104 cod were tagged and released with DSTs in Icelandic waters; of these, $347(31.4 \%)$ were recaptured up to $1807 \mathrm{~d}$ later. Tagging localities at the southwest (SW), southeast (SE), west (W) and northeast coasts (NE) of Iceland were selected for the study (Fig. 1). Spawning cod, 65 to $107 \mathrm{~cm}$ in length, were captured using gillnets off the southern and western coasts and by Danish seine off the NE coast.

\section{Seasonality and timing of migration}

In total, 41 DST-tagged fish were recaptured at least 18 mo after release and were used for the analysis of temporal stability and repetitive behaviour (Supplement 1 at www.int-res.com/articles/suppl/ m462p251_supp.pdf). The classification of behaviour types as coastal versus frontal was performed according to previous studies (Pálsson \& Thorsteinsson 2003, Pampoulie et al. 2008a, Grabowski et al. 2011). In general, coastal and frontal behaviours were defined according to the annual temperature and depth history of the tagged individuals. Coastal types (C) spend at least $70 \%$ of their time in shallow waters showing an annual rise in temperature to a maximum in September/October and decline in temperature to a minimum in February/March. The frontal types (F) share the depth range of the coastal types during spawning migrations, but during feeding migrations, they move to deeper waters $(250$ to $600 \mathrm{~m})$. The temperature history showed visits to thermal fronts and frequent vertical migrations moving between extremes in temperatures typically found at such locations $\left(<0^{\circ} \mathrm{C}\right.$ and $\left.>7^{\circ} \mathrm{C}\right)$.

The temporal stability in depth and temperature profiles between years of each individual was estimated with Pearson correlation between monthly mean depth and temperature of a particular month in 2 consecutive years. Between-year consistency in timing of arrival at, and departure 
from, a spawning ground was tested with analysis of covariance (ANCOVA), with time of migration in the latter year as the dependent variable, time of migration in the former year as a covariate and behaviour type as a random factor. The model is expressed as:

$$
T=\beta_{0}+\beta_{1} \times T_{y+1}+\beta_{2} \times M+\beta_{3}\left(T_{y+1} \times M\right)+\varepsilon
$$

where $T$ is the day of the year in the former year, $T_{y+1}$ is the day of the year in the latter year, $M$ is the behaviour type, $\beta_{0}$ is the intercept, $\beta_{1}, \beta_{2}$ are the slopes for the 2 variables, $\beta_{3}$ is the slope for the interaction term, and $\varepsilon$ is the error term. Timing of arrival and departure was estimated from the behaviour pattern as day of the year. Individual cod are found at lower depths on the spawning grounds than during the feeding migrations. Therefore, patterns are easily seen in the depth profiles (Fig. 2), and the time of arrival on the spawning ground can be estimated from the vertical activity. Periods of low vertical activity, when cod are found at the same depth for more than $2 \mathrm{~d}$ at the end of the migratory period, are characteristic of individuals arriving at the spawning ground. During the following period of low activity, the cod remain at the spawning ground. When the

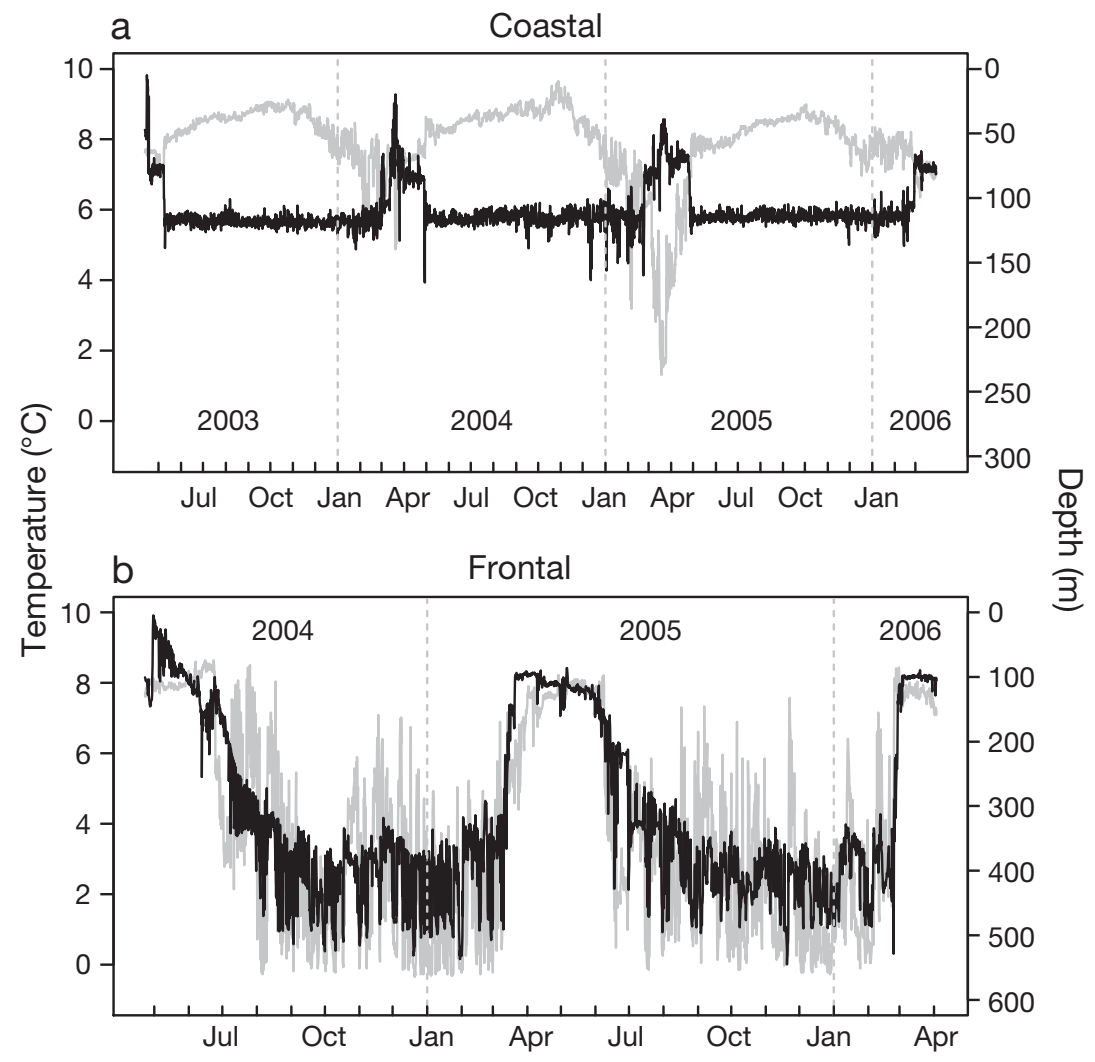

Fig. 2. Gadus morhua. Typical (a) coastal and (b) frontal data storage tag profiles over more than 2 yr. Depth = black line, temperature = grey line behaviour pattern reverts to increased vertical activity, and the cod moves into deeper waters, the fish has left the spawning ground. Eight comparisons of each behaviour type were included in the model, as migration from and to the spawning ground could only be compared using 8 coastal and 8 frontal individuals. Behaviour type was not significant and was removed from the final model for simplification. The new model was expressed as:

$$
T=\beta_{0}+\beta_{1} \times T_{Y+1}+\varepsilon
$$

\section{Estimating location from a tidal model}

The tidal model location was applied to the 41 DSTs retrieved more than 18 mo after release. Measurements of frequency of $6 \mathrm{~h}$ were omitted due to insufficient temporal resolution to detect the tidal oscillation, and the limit was therefore set at $10 \mathrm{~min}$. Furthermore, the fish must stay at the seafloor (at a constant depth), during several hours to cover the tidal wave. A data base of amplitude and phase of 7 tidal harmonic constituents on a $0.25^{\circ}$ longitude and $0.10^{\circ}$ latitude grid was used as a basis for the tidal location of the fish. The data originated from a numerical model of the tides in the North Atlantic Ocean around Iceland, developed by Tómasson \& Káradóttir (2005). The model extends over an area of $5.7 \times 10^{6} \mathrm{~km}^{2}$ with $10 \times 10 \mathrm{~km}$ resolution over the whole model domain but $2 \times 2 \mathrm{~km}$ resolution on the Icelandic shelf. It is based on 7 tidal harmonic constituents and takes boundary conditions at open ocean boundaries from a larger global model (Finite Element Solution, FES 2004; www.aviso.ocean obs.com/en/data/products/auxiliaryproducts/global-tide-fes2004-fes99/ description-fes2004/index.html). The model has been calibrated and verified extensively with data from harbours and mooring stations around Iceland and elsewhere. Its accuracy on the Icelandic shelf is within a few centimetres in amplitude and a few minutes in phase. The tidal location method used here is an extension of that presented by Pedersen et al. (2008). The first step is to search the entire data series for possible tidal patterns. A tidal pattern is identified 
where fitting to a sine curve over a sliding window of $10 \mathrm{~h}$ in length satisfies 3 criteria, i.e. root mean square error (RMSE) $<0.42 \mathrm{~m}$, coefficient of determination $\mathrm{R}^{2}>0.85$ and amplitude of the fitted sine wave A $>0.3 \mathrm{~m}$. The second step, applied when a fit to a sine curve is identified, consists of finding the most probable location of the fish by comparison of the amplitude and phase of the fitted sine curve with calculated tidal signals within the model domain. These steps are identical to those of Pedersen et al. (2008) (except for the criteria on minimum amplitude, which were twice as small in this study to adapt to tidal conditions in the sea around Iceland) resulting in an automatically proposed location of the fish. However, those criteria alone were found to propose too many false or unreliable tidal signals and locations when applied to data from Icelandic cod. Therefore, a third step was added based on the visual comparison of observed tidal DST-pattern of the cod and the modelled tidal oscillation at the predicted location. Based on a comparative evaluation of the agreement between the 2, and an inspection of other possible tidal patterns in nearby time intervals, taking into account cod swimming speed and distance from the last accepted location, a final decision was made on acceptance or rejection of the tidal location. With this additional step, around one-third of the originally proposed tidal patterns and locations were rejected. A more detailed description of the methodology used is given and supported with examples from analysis of the DST pattern of a cod with the tag identification number (tag ID) 2C0645 (Supplement 2 at www.intres.com/articles/suppl/m462p251_supp.pdf). The accuracy and reliability of the predicted tidal locations was verified by applying the method to time series from stationary tags (tags moored at fixed locations). The results showed that if a signal was correctly identified as a tidal signal, the predicted location was reliable with an accuracy of 10 to $20 \mathrm{~km}$ in most cases (see Supplement 3 at www.int-res.com/articles/suppl/ m462p251_supp.pdf for results of the verification).

\section{RESULTS}

\section{Seasonality}

Data retrieved from the 41 individual DSTs revealed a high degree of inter-annual regularity in temperature and depth patterns, with a typical pattern of coastal cod inhabiting the same depths and temperatures during $3 \mathrm{yr}$ (Fig. 2) and a typical pattern of frontal cod visiting the same depths over a period of $2 \mathrm{yr}$ at low and fluctuating temperatures, and returning to shallower water at a fairly constant time of the year (Fig. 2).

The 2 behaviour types clearly displayed distinct seasonal patterns of temperature and depth (Figs. 2 \& 3 ), and individuals of both types retained their behaviour characteristics through the observation time, i.e. coastal behaviour types did not demonstrate frontal behaviour patterns or vice versa. The annual temperature patterns of coastal cod were characterised by typical sinusoidal curves in all areas with minimum values during the spawning season and maximum values in autumn. The temperature pattern of coastal cod was fairly uniform in the southern areas and not different from the mean, but lower in the NE area (Fig. 3e,g). Similarly, the period of minimum temperatures lasted longer in the NE area than in the south. The annual temperature patterns of frontal cod in the southern areas were basically reversed to that of coastal cod, with maximum temperatures during the spawning season, but minimum temperatures during the feeding season. The patterns were not different among the 3 investigated areas (Fig. 3f). In the southern areas, the temperatures of frontal cod declined abruptly after the spawning season to a minimum level until late autumn or winter. At the same time, variability (first and third quantiles) in temperature and depth increased substantially indicating foraging activity at thermal fronts. In the NE area, however, the annual temperature patterns were similar between the 2 behaviours, with maximum values in autumn, but lower values were observed in the frontal group. However, increased temperature range was seen in the frontal group in the NE area from June through November, indicating increased activity at thermal fronts (Fig. 3g,h).

The depth patterns of coastal cod showed largely similar trends across areas with shallowest distributions in April at the time of peak spawning, although the depth pattern in the NE area was shallower (Fig $3 a, c)$. The observed depth distribution patterns of frontal cod were more highly pronounced than for the coastal type, showing clear migrations into shallower waters during the spawning season in March and April, followed by migrations into deeper waters, associated with increased variability in depth, and reaching maximum depths in autumn (Fig. 3b,d). The frontal cod in the NE area inhabited shallower waters than frontal cod in the other areas in all months (Fig. 3d). The temperature and depth patterns of the coastal and frontal behaviours indicate considerable separation during feeding migrations, but similar habitats during the spawning season in February to 

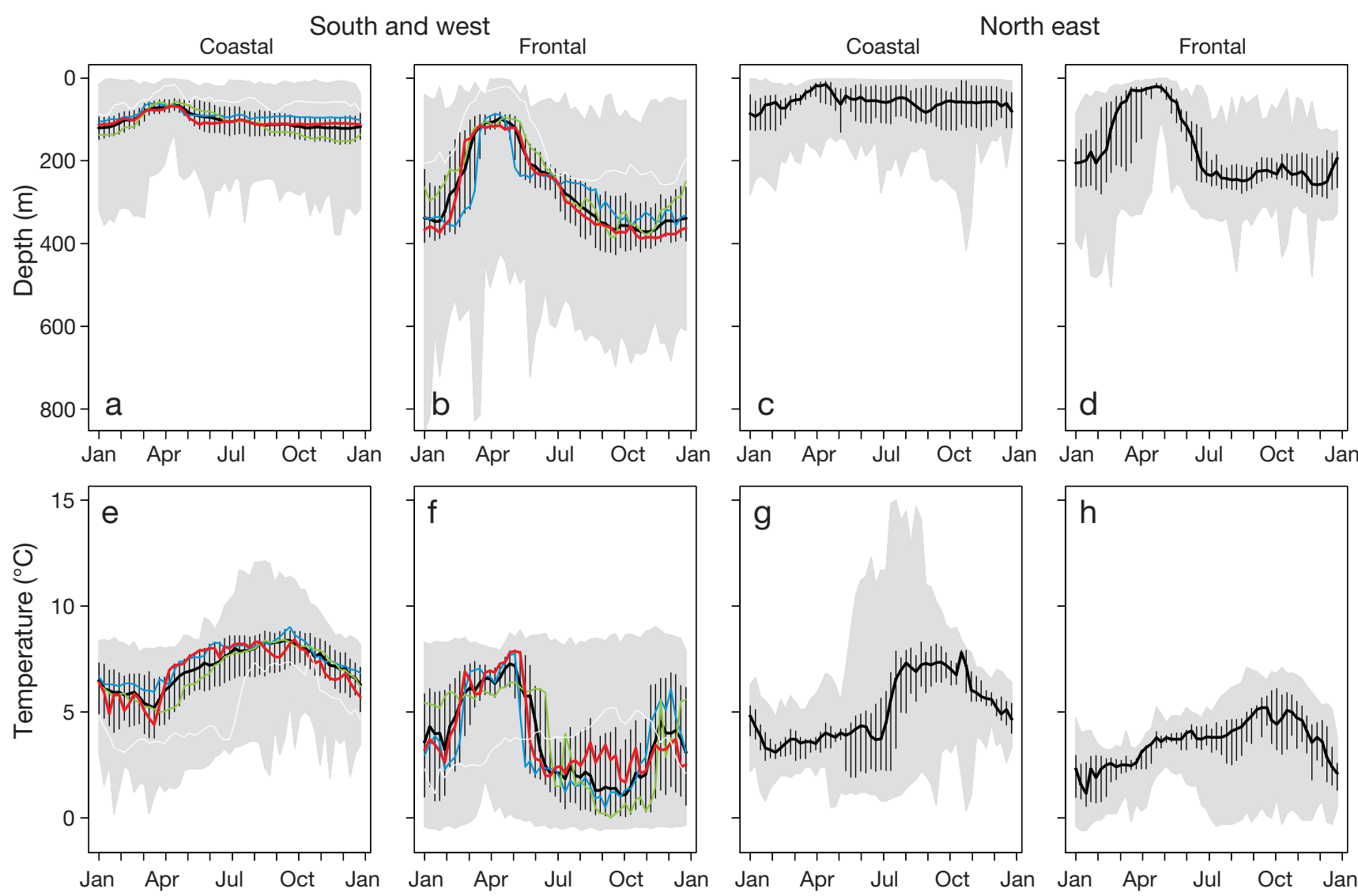

Fig. 3. Gadus morhua. Weekly depth and temperature profiles (median \pm first and third quantiles) for $(\mathrm{a}, \mathrm{C}, \mathrm{e}, \mathrm{g}) \mathrm{coastal}$ and $(\mathrm{b}$, $d, f, h)$ frontal cod. Grey shading shows weekly minimum and maximum depth and temperature. South west (red), south east (blue), west (green), north east (white in $a, b, e, f$, black in $c, d, g, h)$ and combined south and west areas (black in a, b, e, f)

May when sexually mature fish of both behaviour types are located in coastal waters. In addition, the comparison of migration patterns of both behaviours showed that individuals consistently occupied similar depth/temperature niches during the same month in consecutive years (Table 1). Only 4 out of 53 comparisons were not correlated in mean monthly temperature and depth between 2 consecutive years (Table 1). Exception to the high degree of interannual regularity were also observed (Table 1), such as 2 frontal cod (tag ID 1C0480 and 1C1477) which showed typical behaviour patterns except in spawning time, where they appeared to have skipped spawning.

\section{Timing of migration}

Individuals of both behaviour types arrived at the spawning grounds around mid-March and left for the feeding grounds at various times from the end of May to the end of June. Although based on a relatively small number of samples ( $\mathrm{n}=8$ for each behaviour), the arrival on the spawning ground in the second year was significantly related to that of the first year (ANCOVA; $F=5.274 ; \mathrm{p}=0.038$ ). No significant differences could be observed between dates of arrival at spawning grounds of the behaviour types. Likewise, the departure from the spawning ground in the second year was significantly related to departure in the first year $\left(\mathrm{ANCOVA}_{i} F=6.312 ; \mathrm{p}=0.0249\right.$ ), and no differences were observed between behaviour types.

\section{Geo-location and shoal migration}

Geographic positions of 2 coastal individuals tagged at similar locations (Fig. 4) showed that they stayed within the same bay during the 2 yr time series. The tidal model furthermore showed that coastal individuals were repeatedly found close to each other (10 to $20 \mathrm{~km}$ ) during 3 seasons (Fig. 5), which tends to confirm that they moved together in a concurrent way and exhibited fidelity to migrating routes, areas and groups or shoals. The tidal location 
Table 1. Gadus morhua. Pearson's correlation between mean depth $\left(\mathrm{r}_{\mathrm{d}}\right)$ and mean temperature $\left(\mathrm{r}_{\mathrm{t}}\right)$ of a particular month and the same month in the following year for (a) coastal and (b) offshore cod (recapture after at least $18 \mathrm{mo}$ ). The period from April to March in 2 consecutive years was compared. In cases where recaptures were earlier, the period from April to the time of recapture was compared (September to February). Tag ID: data storage tag identification. df: degrees of freedom; $\mathrm{p}$ : $\mathrm{p}$ values for mean depth $\left(\mathrm{p}_{\mathrm{d}}\right)$ and mean temperature $\left(\mathrm{p}_{\mathrm{t}}\right)$; bold values indicate significance at $\alpha=0.05$

\begin{tabular}{|c|c|c|c|c|c|c|}
\hline Tag ID & $\mathrm{df}$ & $r_{d}$ & $\mathrm{p}_{\mathrm{d}}$ & $r_{t}$ & $\mathrm{p}_{\mathrm{t}}$ & Periods compared \\
\hline \multicolumn{7}{|c|}{ a) Coastal cod } \\
\hline $3 \mathrm{C} 0306$ & 10 & 0.52 & 0.084 & 0.79 & $<0.001$ & $2005 / 2006$ and $2006 / 2007$ \\
\hline $2 \mathrm{C} 0378$ & 10 & 0.85 & $<0.001$ & 0.84 & $<0.001$ & $2005 / 2006$ and $2006 / 2007$ \\
\hline $2 \mathrm{C} 0378$ & 4 & 0.91 & $<0.001$ & 0.99 & $<0.001$ & 2006 and 2007 \\
\hline $1 \mathrm{C} 0397$ & 10 & 0.006 & 0.985 & 0.82 & 0.001 & $2003 / 2004$ and $2004 / 2005$ \\
\hline 1C0397 & 9 & 0.31 & 0.356 & 0.83 & 0.001 & $2004 / 2005$ and $2005 / 2006$ \\
\hline $2 \mathrm{C} 0404$ & 10 & 0.76 & 0.004 & 0.89 & $<0.001$ & $2005 / 2006$ and $2006 / 2007$ \\
\hline $1 \mathrm{C} 0407$ & 10 & 0.95 & $<0.001$ & 0.79 & 0.002 & $2003 / 2004$ and $2004 / 2005$ \\
\hline $1 \mathrm{C} 0407$ & 10 & 0.98 & $<0.001$ & 0.62 & 0.030 & $2004 / 2005$ and $2005 / 2006$ \\
\hline $2 \mathrm{C} 0417$ & 10 & 0.90 & $<0.001$ & 0.86 & $<0.001$ & $2003 / 2004$ and $2004 / 2005$ \\
\hline $2 \mathrm{C} 0417$ & 10 & 0.97 & $<0.001$ & 0.56 & 0.060 & $2004 / 2005$ and $2005 / 2006$ \\
\hline $1 \mathrm{C} 0431$ & 4 & 0.42 & .408 & 0.94 & 0.005 & \\
\hline $1 \mathrm{C} 0444$ & 10 & 0.87 & $<0.001$ & 0.96 & $<0.001$ & 005 \\
\hline $1 \mathrm{C} 0503$ & 6 & 0.85 & 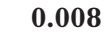 & 0.90 & 0.0 & 2 \\
\hline $2 \mathrm{C} 1517$ & 10 & 0.75 & .0 & & $0 .($ & 007 \\
\hline $2 \mathrm{C} 0641$ & 5 & 0.35 & 0.4 & & $<0.0$ & \\
\hline $2 \mathrm{C}$ & 5 & 0. & 3 & & & \\
\hline $3 \mathrm{C} 0650$ & 4 & -0.60 & p & & $0 . c^{-1}$ & 05 \\
\hline $1 \mathrm{C} 1166$ & 10 & 0.37 & 0.2 & 0.92 & $<0$. & $005 / 2006$ \\
\hline $1 \mathrm{C} 1166$ & 10 & 0.56 & 0.0 & 0.83 & $<0.001$ & 006 and $2006 / 2007$ \\
\hline 1C1195 & 9 & 0.97 & $<0.0$ & 0.75 & 0.008 & 005 and $2005 / 2006$ \\
\hline $1 \mathrm{C} 1224$ & 6 & 0.01 & .9 & 0.62 & 0.104 & 2005 \\
\hline $1 \mathrm{C} 1225$ & 10 & -0.12 & $0.6 !$ & 0.23 & 0.462 & /2004 and 2004/2005 \\
\hline $1 \mathrm{C} 1231$ & 4 & -0.49 & 0.328 & 0.84 & 0.038 & 2005 \\
\hline $1 \mathrm{C} 1240$ & 10 & 0.78 & 0.003 & 0.49 & 0.104 & $2004 / 2005$ and $2005 / 2006$ \\
\hline 1C1282 & 8 & .9 & $<0.001$ & 0.50 & 0.146 & 5 and 2005/2006 \\
\hline 2C1489 & 10 & .87 & 00 & .94 & 0.001 & $006 / 2007$ \\
\hline \multicolumn{7}{|c|}{ b) Frontal cod } \\
\hline $2 \mathrm{C} 0426$ & 10 & .77 & 003 & 0.88 & $<0.001$ & 2007 \\
\hline $2 \mathrm{C} 0444$ & 10 & 0.39 & 2 & 0.66 & 9 & $006 / 2007$ \\
\hline $1 \mathrm{C} 0480$ & 10 & 0.06 & 9 & -0.04 & 0.9 & $04 / 2005$ \\
\hline 20 & 10 & 0.92 & $<0.0$ & 33 & $<$ & 005 \\
\hline 2 & 10 & 6 & $<$ & 5 & $<$ & 006 \\
\hline 5 & 10 & 0.89 & $<$ & 30 & & 005 \\
\hline 85 & 10 & 93 & $<0.0$ & 57 & 3 & 006 \\
\hline $1 \mathrm{C}$ & 10 & 0.75 & $\mathbf{0}$ & 0 . & 0. & 005 \\
\hline $1 \mathrm{C} 0595$ & 10 & 0.84 & $<0.001$ & 0.95 & $<0.001$ & $2003 / 2004$ and $2004 / 2005$ \\
\hline $1 \mathrm{C} 0605$ & 10 & 0.76 & 0.004 & 0.85 & $<0.001$ & $2003 / 2004$ and $2004 / 2005$ \\
\hline $1 \mathrm{C} 0611$ & 10 & 0.92 & $<0.001$ & 0.88 & $<0.001$ & $2003 / 2004$ and $2004 / 2005$ \\
\hline $1 \mathrm{C} 0611$ & 9 & 0.67 & 0.024 & 0.55 & 0.082 & $2004 / 2005$ and $2005 / 2006$ \\
\hline $2 \mathrm{C} 0669$ & 10 & 0.72 & 0.008 & 0.88 & $<0.001$ & $2004 / 2005$ and $2005 / 2006$ \\
\hline 1C1198 & 8 & 0.91 & $<0.001$ & 0.97 & $<0.001$ & $2004 / 2005$ and $2005 / 2006$ \\
\hline $1 \mathrm{C} 1146$ & 10 & 0.46 & 0.133 & 0.68 & 0.014 & $2003 / 2004$ and $2004 / 2005$ \\
\hline $1 \mathrm{C} 1146$ & 10 & 0.54 & .067 & 0.74 & 0.006 & $2004 / 2005$ and $2005 / 2006$ \\
\hline 1C1164 & 10 & 0.83 & $<0.001$ & 0.83 & $<0.001$ & $2004 / 2005$ and $2005 / 2006$ \\
\hline $1 \mathrm{C} 1164$ & 10 & 0.88 & $<0.001$ & 0.80 & $<0.001$ & $2005 / 2006$ and $2006 / 2007$ \\
\hline $1 \mathrm{C} 1244$ & 4 & 0.99 & $<0.001$ & 0.53 & 0.283 & 2004 and 2005 \\
\hline $1 \mathrm{C} 1426$ & 10 & 0.74 & 0.006 & 0.69 & 0.013 & $2004 / 2005$ and $2005 / 2006$ \\
\hline $1 \mathrm{C} 1448$ & 10 & 0.93 & $<0.001$ & 0.78 & 0.003 & $2004 / 2005$ and $2005 / 2006$ \\
\hline $1 \mathrm{C} 1477$ & 10 & -0.43 & .164 & -0.45 & 0.138 & $2004 / 2005$ and $2005 / 2006$ \\
\hline $1 \mathrm{C} 1480$ & 10 & 0.84 & $<0.001$ & 0.44 & 0.157 & $2004 / 2005$ and $2005 / 2006$ \\
\hline $1 \mathrm{C} 1480$ & 10 & 0.97 & $<0.001$ & 0.80 & 0.002 & $2005 / 2006$ and $2006 / 2007$ \\
\hline 2C1492 & 10 & 0.83 & $<0.001$ & 0.77 & 0.003 & $2005 / 2006$ and $2006 / 2007$ \\
\hline 3C1499 & 10 & 0.84 & $<0.001$ & 0.79 & 0.002 & $2005 / 2006$ and $2006 / 2007$ \\
\hline 3C1499 & 3 & 0.90 & 0.036 & 0.98 & 0.004 & 2006 and 2007 \\
\hline
\end{tabular}

data including all recovered DSTs (Fig. 5) also showed that during spawning time and spawning migrations (February to May), individuals of each behaviour type were distributed in the same area, but frontal cod occupied deeper parts of the spawning grounds compared to the coastal cod. In the summer (June to September) and winter feeding migrations (October to January) the distributions were uneven, as coastal cod were more prominent in shallow waters in the south, SW and SE. Frontal cod were mostly found in deeper waters in the north, NW and NE, where they were likely to encounter polar temperature fronts. In addition, most
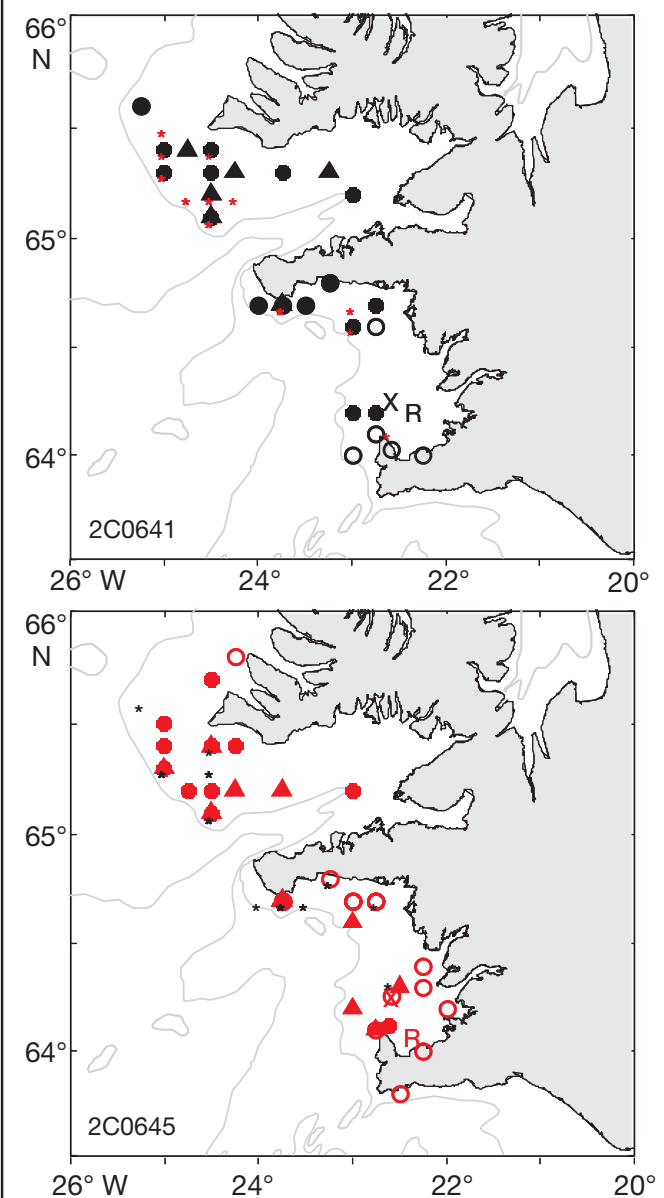

Fig. 4. Gadus morhua. Example of geolocation of 2 coastal individuals (2C0641, black; 2C0645, red) which stayed together for 2 yr. Symbols show locations in February to May (O), June to September ( $(\mathbf{\Lambda})$, October to January $(\bullet)$; location of other individual $(*)$, release $(\mathrm{R})$ and recapture $(\mathrm{x})$ locations 

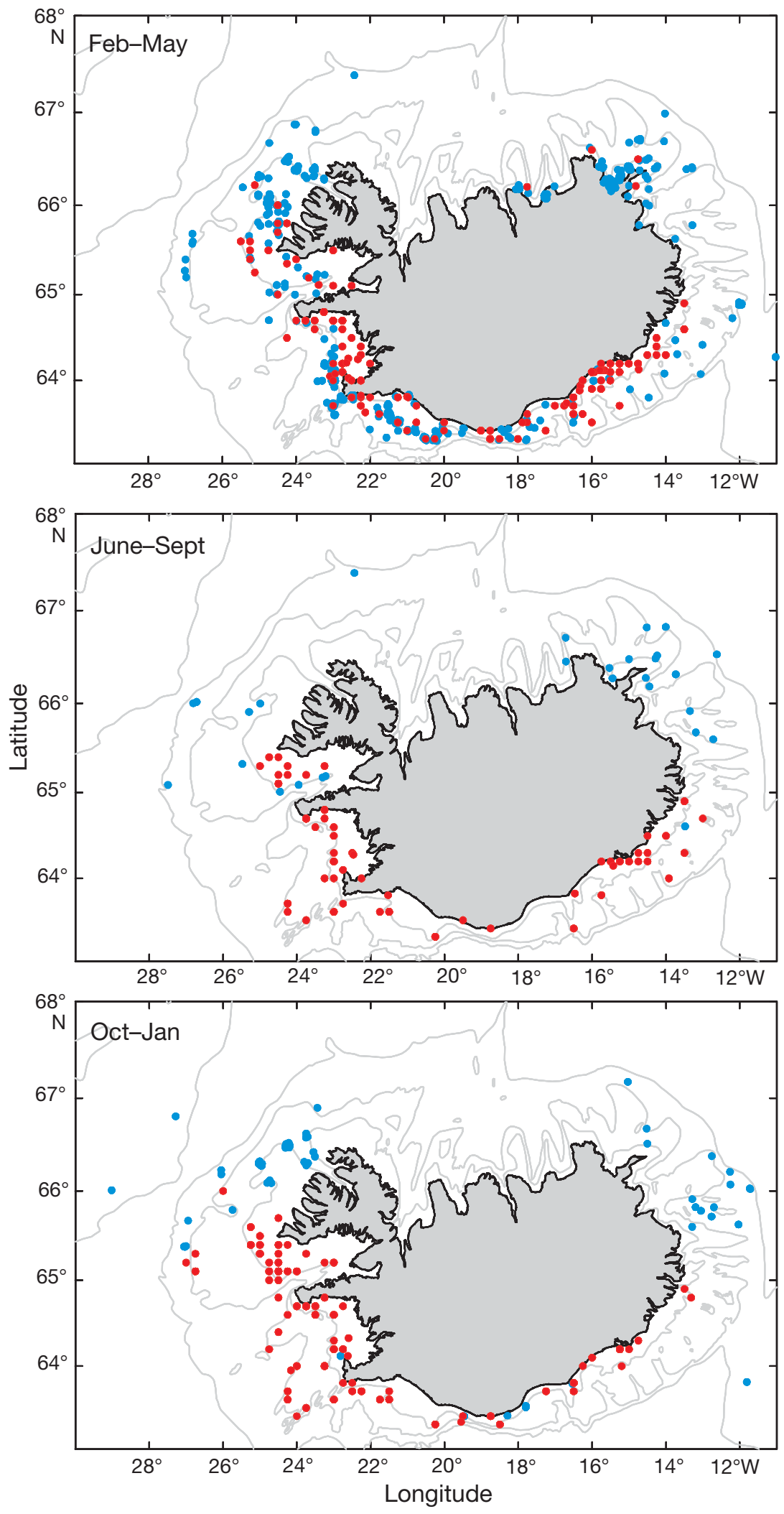

Fig. 5. Gadus morhua. Geo-location of individual cod (coastal $=$ red; frontal = blue) based on an improved model of Pedersen et al. (2008). All individuals

(41) are presented by regions and seasons tagged individuals exhibited spawning site fidelity, as they were recaptured at the same GPS location where they were released (data not shown).

\section{DISCUSSION}

The development of new tracking methods has provided a unique opportunity to study the spatio-temporal variability of individual migration patterns over more than 1 annual cycle. In this study, using information retrieved from DSTs placed in individual Atlantic cod, the consistency in DSTs profiles, timing of migration and geo-location of coastal and frontal behaviour types over more than 18 mo were investigated for the first time. The results revealed that (1) coastal and frontal behaviour types clearly display distinct seasonal thermobathymetric patterns which are constant from year to year, (2) the onset of migration is consistent from year to year, (3) DST tidal signatures suggest feeding migrations in shoals. These results are the first for Icelandic cod, and each of the above issues is discussed below in more detail.

Although some variation could be observed among regions within types, the 2 behaviour types demonstrated highly consistent and repetitive patterns over the period investigated. Individual coastal cod, moving all year within coastal waters, showed a considerable range in temperatures outside the spawning season, indicating that their feeding habitats may differ in temperature regime within the coastal environment. This also indicates that the coastal cod may travel some distance along the coast during the feeding migrations, a result corroborated by tidal locations of this behaviour type during feeding migrations. On the other hand, the frontal cod migrated out of their spawning grounds at variable temperature and depth, and displayed an extensive, vertical and horizontal 
migratory behaviour and a clear separation from the coastal type. Further characteristics of the behaviour of the frontal cod were annual, repeated visits to sub0 waters, a pattern which was never observed for the coastal type. The results also demonstrate strong, repetitive thermal-bathymetric patterns across 2 or 3 yr. In addition, individuals of both types retained their behaviour characteristic through the observation time, i.e. a coastal type did not demonstrate frontal behaviour patterns or vice versa. Real intermediate characters were not found, although 5 coastal cod were recorded at depth $>200 \mathrm{~m}$ in feeding migrations and were classified as intermediates. Those fish nevertheless displayed a temperature history of a coastal cod (Grabowski et al. 2011).

The timing of a migration from spawning to feeding ground and vice versa, which is crucial for individual survival and reproductive success, has been shown to be related either to food availability and temperature (Bell 2011, Schaefer et al. 2011) or to genetic inheritance (Quinn et al. 2000, Pulido et al. 2001). Here, the timing of migrations in 2 successive years was correlated, suggesting a consistency in the onset of migration for each behaviour type. A successful migration strategy would imply the retainment of migratory behaviours for the benefit of reduced food competition (Brodersen et al. 2012). The consistency observed here might reflect successful, concurrent strategies to avoid resource competition within a large, coastal population. A recent stomach content analysis of inshore versus offshore cod, supportive of this hypothesis, showed a frontal cod diet of capelin and the deep-water northern ambereye Hymenodora glacialis, a diet unlikely for coastal cod within the feeding season (Jónsdóttir et al. in press). Individual consistency in the timing of migrations, and the destination of winter feeding migrations, has been mentioned for freshwater fish (Brodersen et al. 2012). For marine fish, however, this seems to be the first observation. The direction and timing of feeding or winter migrations have also been shown to be under genetic control in bird populations (Helbig et al. 1994, Pulido et al. 2001) and freshwater fish (Quinn et al. 2000). Both frontal and coastal behaviours exhibit different genotypes at the pantophysin locus (Pampoulie et al. 2008a), which might suggest some genetic basis or at least differences among the 2 behaviour types, but further genetic investigations have to be performed to assess whether the observed migration pattern has a genetic basis. However, the fact that individuals of both types retain their behavioural characteristics through the observation time, i.e. the coastal behaviour type never changed to the frontal behaviour type or vice versa, tends to suggest that a genetic basis might be responsible for the difference in feeding strategy. In Norwegian waters, differences in the blood type E, the haemoglobin $H b-\mathrm{I}^{1}$ allele and the Pan I locus have led to the suggestion that these cod behaviour types represent sibling species (Møller 1969).

Finally, one of the most striking observations during the present study was that the tidal location model suggested that the feeding migrations of cod in Icelandic waters were undertaken in groups or shoals during the whole year. Shoaling is commonly described as groups of fishes that remain together for social reasons with no implication of structure or function (Pitcher 1983, Pitcher \& Parrish 1993). Shoaling, or social transmission of migration routes and homing, has been proposed to explain discrepancies among tagging and genetic data in Icelandic cod (Pampoulie et al. 2008b). One possible explanation for the observed results is therefore that social transmission might enable the rapid transfer of beneficial behavioural traits (feeding migration, homing and timing of the migration) from older spawning cod to new recruits (see 'adopted migrant' hypothesis of McQuinn 1997).

Behaviour types, i.e. groups of individuals within the same stock exhibiting different patterns of migration, are part of the life-history portfolio of a species (Greene et al. 2010, Schindler et al. 2010), yet very little information exists on their consequences for the conservation of exploited marine resources. Behavioural effects on vulnerability to harvest have only been recently investigated (Biro \& Post 2008), and revealed that more active and bold fish, for example migratory fish, are likely to be more vulnerable to harvest than sedentary fish (Biro \& Post 2008). Therefore, the frontal behaviour is likely to be more vulnerable to fishing pressure than the coastal one, and sustainable fisheries require a more complex management practice than the one currently applied. One of the possibilities to avoid the possible overexploitation of this behaviour type would be to apply quotas on the different fishing gears (fishing at different depth), or quotas to different geographical areas which will be proxy of the depth distribution of the different behaviour types as a precautionary approach.

Determining the mechanisms maintaining these 2 consistent behaviour types remains a challenge, and requires further analyses and studies, but the consistent migration pattern is an interesting evolutionary case to investigate. At present, it is difficult to assess whether these migration patterns have a genetic 
basis (inheritance), or imply an 'on-going' ecological speciation due to the use of different food resources (Keller \& Seehausen 2012).

Acknowledgements. This research was carried out under the METACOD and CODYSSEY EU-projects (Q5RS-200100953 and Q5RS-2002-00813). We thank all vessel crews and researchers for their assistance with sampling. Special thanks to S. Helyar, who improved an early version of the manuscript, and to 3 anonymous referees for their useful comments.

\section{LITERATURE CITED}

Bell CP (2011) Resource buffering and the evolution of bird migration. Evol Ecol 25:91-106

Biro PA, Post JR (2008) Rapid depletion of genotypes with fast growth and bold personality traits from harvested fish populations. Proc Natl Acad Sci USA 105:2919-2922

Brodersen J, Nilsson PA, Chapman BB, Skov C, Hansson LA, Brönmark C (2012) Variable individual consistency in timing and destination of winter migrating fish. Biol Lett 8:21-23

Egevang C, Stenhouse IJ, Phillips RA, Petersen A, Fox JW, Silk JRD (2010) Tracking of Arctic terns Sterna paradisaea reveals longest animal migration. Proc Natl Acad Sci USA 107:2078-2081

Fevolden SE, Pogson GH (1997) Genetic divergence at the synaptophysin (Syp I) locus among Norwegian coastal and north-east Arctic populations of Atlantic cod. J Fish Biol 51:895-908

- Forsythe PS, Crossman JA, Bello NM, Baker EA, Scribner KT (2012) Individual-based analyses reveal high repeatability in timing and location of reproduction in lake sturgeon (Acipenser fulvescens). Can J Fish Aquat Sci 69: 60-72

Godo OR, Michalsen K (2000) Migratory behaviour of northeast Arctic cod, studied by use of data storage tags. Fish Res 48:127-140

Grabowski TB, Thorsteinsson V, McAdam BJ, Marteinsdóttir G (2011) Evidence of segregated spawning in a single marine fish stock: sympatric divergence in Icelandic cod? PLoS ONE 6:e17528

Greene CM, Hall JE, Guilbault KR, Quinn TP (2010) Improved viability of populations with diverse life-history portfolios. Biol Lett 6:382-386

Helbig AJ, Berthold PP, Mohr G, Querner U (1994) Inheritance of a novel migratory direction in central European blackcaps. Naturwissenschaften 81:184-186

Hunter E, Metcalfe JD, Arnold GP, Reynolds JD (2004) Impacts of migratory behaviour on population structure in North Sea plaice. J Anim Ecol 73:377-385

Jónsdóttir IG, Björnsson H, Skúladóttir U (in press) Comparative study on the predation by Atlantic cod Gadus morhua on northern shrimp Pandalus borealis in inshore and offshore areas of Iceland. Mar Ecol Prog Ser doi: 10.3354/meps09977

> Keller I, Seehausen O (2012) Thermal adaptation and ecological speciation. Mol Ecol 21:782-799

- Klaassen RHG, Alerstam T, Carlsson P, Fox JW, Lindstrom A (2011) Great flights by great snipes: long and fast nonstop migration over benign habitats. Biol Lett 7:833-835
Matthews CJD, Luque SP, Petersen SD, Andrews RD, Ferguson SH (2011) Satellite tracking of a killer whale (Orcinus orca) in the eastern Canadian Arctic documents ice avoidance and rapid, long-distance movement into the North Atlantic. Polar Biol 34:1091-1096

McQuinn IH (1997) Metapopulations and the Atlantic herring. Rev Fish Biol Fish 7:297-329

Metcalfe JD (2006) Fish population structuring in the North Sea: understanding processes and mechanisms from studies of the movements of adults. J Fish Biol 69:48-65

Møller D (1969) The relationship between arctic and coastal cod in their immature stages illustrated by frequencies of genetic characters. Fiskeridir Skr Ser Havunders 15: 220-233

> Neat FC, Wright PJ, Zuur AF, Gibb IM and others (2006) Residency and depth movements of a coastal group of Atlantic cod (Gadus morhua L.). Mar Biol 148:643-654

Nordeide JT (1998) Coastal cod and north-east Arctic cod Do they mingle at the spawning grounds in Lofoten? Sarsia 83:373-379

Olifiers N, Loretto D, Rademaker V, Cerqueira R (2011) Comparing the effectiveness of tracking methods for medium to large-sized mammals of Pantanal. Zoologia (Curitiba) 28:207-213

Pálsson ÓK, Thorsteinsson V (2003) Migration patterns, ambient temperature, and growth of Icelandic cod (Gadus morhua): evidence from storage tag data. Can J Fish Aquat Sci 60:1409-1423

Pampoulie C, Jakobsdóttir KB, Marteinsdóttir G, Thorsteinsson V (2008a) Are vertical behaviour patterns related to the Pantophysin locus in the Atlantic cod (Gadus morhua L.)? Behav Genet 38:76-81

> Pampoulie C, Stefánsson MÖ, Jörundsdóttir TD, Danilowicz BS, Daníelsdóttir AK (2008b) Recolonization history and large scale dispersal in the open sea: the case study of the North Atlantic cod, Gadus morhua L. Biol J Linn Soc 94:315-329

> Pedersen MW, Righton D, Thygesen UH, Andersen $\mathrm{KH}$, Madsen H (2008) Geolocation of North Sea cod (Gadus morhua) using hidden Markov models and behavioural switching. Can J Fish Aquat Sci 65:2367-2377

> Pitcher TE (1983) Heuristic definitions of shoaling behaviour. Anim Behav 31:611-613

Pitcher TJ, Parrish JK (1993) Functions of shoaling behaviour in teleosts. In: Pitcher TJ (ed) Behaviour of teleost fishes. Chapman \& Hall, London, p 363-440

Pulido F, Berthold P, Mohr G, Querner U (2001) Heritability of the timing of autumn migration in a natural bird population. Proc R Soc Lond B Biol Sci 268:953-959

Quinn TP, Unwin MJ, Kinnison MT (2000) Evolution of temporal isolation in the wild: genetic divergence in timing of migration and breeding by introduced Chinook salmon populations. Evolution 54:1372-1385

Sarvas TH, Fevolden SE (2005) Pantophysin (Pan I) locus divergence between inshore v. offshore and northern v. southern populations of Atlantic cod in the north-east Atlantic. J Fish Biol 67:444-469

Schaefer KM, Fuller DW, Block BA (2011) Movements, behavior, and habitat utilization of yellowfin tuna (Thunnus albacares) in the Pacific Ocean off Baja California, Mexico, determined from archival tag data analyses, including unscented Kalman filtering. Fish Res 112: $22-37$

Schindler DE, Hilborn R, Chasco B, Boatright CP, Quinn TP, Rogers LA, Webster MS (2010) Population diversity and 
the portfolio effect in an exploited species. Nature 465 : 609-612

Skarstein TH, Westgaard JI, Fevolden SE (2007) Comparing microsatellite variation in north-east Atlantic cod (Gadus morhua L.) to genetic structuring as revealed by the pantophysin (Pan I) locus. J Fish Biol 70:271-290

Tómasson GG, Káradóttir ÓR (2005) A two dimensional numerical model of astronomical tide and storm surge in

Editorial responsibility: Konstantinos Stergiou, Thessaloniki, Greece the North Atlantic Ocean. In: Viggosson G (ed) Second International Coastal Symposium in Iceland. Höfn, Hornafjörður, 5-8 June, 2005,

Icelandic Maritime Administration, Abstract volume, p 266267

Vardanis Y, Klaassen RHG, Strandberg R, Alerstam T (2011) Individuality in bird migration: routes and timing. Biol Lett 7:502-505

Submitted: February 24, 2012; Accepted: May 28, 2012

Proofs received from author(s): August 7, 2012 